\title{
Manifestação do Devido Processo Legal na Conciliação e na Mediação Judicial
}

\author{
Manifestation of Due Process of Law in Judicial Mediation
}

Nilsiton Rodrigues de Andrade Aragão'

'Universidade de Fortaleza - UNIFOR, Brasil

\section{Resumo}

\begin{abstract}
O presente trabalho se propõe a expor e analisar as transformações ocorridas com o advento do novo Código de Processo Civil e da Lei de Mediação no que diz respeito à manifestação do devido processo legal na conciliação e mediação judicial. Procurase definir formas de melhorar o acesso à justiça, por meio do estabelecimento de um ambiente de processo conducente a posições cooperativas e consensuais na gestão de conflitos, sem que isso implique violação das garantias do devido processo legal.
\end{abstract}

Palavras-chave: Gestão consensual de conflitos; Mediação; Código de Processo Civil; Devido processo legal

\begin{abstract}
This work intends to expose and analyze transformations occurred with the advent of the new Brazilian Code of Civil Procedure and the Mediation Law with regard to Manifestation of due process of law in judicial mediation. It seeks to define ways to improve access to justice by establishing a process environment conducive to cooperative and consensual positions in the management of conflicts, without this implying violations of the guarantees of due process.
\end{abstract}

Keywords: Consensual conflict management; Mediation; Brazilian Code of Civil Procedure; Due process of law

\section{Introdução}

A conciliação e a mediação são, em sua origem, métodos de gestão de conflitos tipicamente extrajudiciais. A sua institucionalização judicial apresenta-se, portanto, como a inclusão de um instituto consagradamente privado em um ambiente público. Nessa condição, a sua assimilação pelo sistema de justiça não é uma prática que se efetive de forma espontânea, sem transformações pontuais para viabilizar a acomodação de elementos de sistemas díspares.

A incorporação das diversas técnicas de gestão consensual de conflitos à realidade judicial, embora, a princípio, possa soar paradoxal ou contraditória em alguns aspectos, por mesclar institutos de bases filosóficas distintas, tem se mostrado não só possível como favorável à consecução dos objetivos do Poder Judiciário.

Ao observar a incorporação do regramento da conciliação e da mediação ao projeto do Código de Processo Civil, ainda durante sua tramitação legislativa, percebe-se que ele ingressa, em princípio, como uma unidade de certo modo compartimentada, ainda que na redação final já apresentasse 
manifestações mais sistemáticas. Por essa razão, a conciliação e a mediação se apresentam como um microsistema dotado de certa autonomia.

Porém, ainda que essas regras não fossem em princípio plenamente integradas, sua inclusão no Código de Processo Civil estimulou o diálogo entre os diversos institutos, fazendo com que os dois saíssem modificados dessa interação. Essas adaptações evolutivas não importam em deturpações na essência do seu propósito ou nos seus princípios informativos, consistem apenas em ajustamentos pontuais a uma realidade diversa de manifestação.

Com base nas experiências já vivenciadas nos últimos anos, é possível verificar os principais impactos da influência recíproca que o processo judicial e a conciliação/mediação judicial exercem um sobre o outro. Alguns aspectos são mais perceptíveis, como a tendência à procedimentalização da conciliação e da mediação e a maior abertura do processo judicial para a autocomposição.

Por consequência, começa-se a perceber a necessidade de respeito ao devido processo legal ao passo que esses métodos de promoção à autocomposição passam a assumir a condição de ato processual. Para melhor definir o objeto do presente estudo, a análise da manifestação do devido processo legal será feita no âmbito da própria sessão de conciliação ou de mediação. Dessa forma, não serão abordadas questões relacionadas a vícios em atos processuais prévios ou preparatórios como a petição inicial, despacho inicial, a citação, etc.

\section{O Devido Processo Legal Mínimo}

Os meios autocompositivos, mesmo quando realizados no âmbito judicial, não se enquadram plenamente às características tidas essenciais à sua definição como atividade jurisdicional, como a aplicação do direito ao caso concreto, a substituição da vontade das partes e a imperatividade. ${ }^{1}$ Por essa razão, a doutrina processualista costuma enquadrar a mediação e a conciliação como "equivalentes jurisdicionais", uma vez que não possuem as características próprias da jurisdição, mas igualmente permitem a tutela de direitos. ${ }^{2}$

Por essa condição específica, não é possível simplesmente transpor a lógica de incidência do devido processo legal para a conciliação e a mediação judicial. O devido processo legal, quase em sua integralidade, foi originalmente concebido sob a perspectiva jurisdicional adjudicatória, com o propósito de assegurar um julgamento justo pelo representante do Estado. A razão de ser dessa construção conceitual é o fato de o princípio voltar-se para a defesa das partes quanto à privação da liberdade ou de bens por decisões judiciais arbitrárias (art. 5.․, LIV, da CF/1988).

Na mediação, "ninguém será privado da liberdade ou de seus bens". O que ocorre é uma disposição voluntária, baseada na autonomia privada. Por isso, o caráter consensual e não adjudicatório da autocomposição reduz a imposição de proteção do devido processo legal, por exigir um nível de controle procedimental muito menor. Alguns autores chegam a defender que a disponibilidade dos bens e a autonomia privada que vigoram na conciliação e na mediação afastam por completo a relação do devido processo legal com as vias autocompositivas. ${ }^{3}$

1 É o que defende Heitor Vitor Mendonça Sica: “Considerando-se as características primordiais da jurisdição, essas atividades que visam a composição amigável, embora judiciais, não poderiam ser consideradas propriamente jurisdicionais, por lhes faltarem diversas das características que conotam o exercício desse poder”. (SICA, Heitor Vitor Mendonça. Velhos e novos institutos fundamentais do direito processual civil. In: ZUFELATO, Camilo; YARSHELL, Flávio Luiz (org.). 40 anos da teoria geral do processo no Brasil: passado, presente e futuro. São Paulo: Malheiros, 2013. p. 430-466, p. 434).

2 É o que faz Fredie Didier Jr.: "Equivalentes jurisdicionais são as formas não jurisdicionais de solução de conflitos. São chamados de equivalentes exatamente porque não sendo jurisdição, funcionam como técnica de tutela de direitos, resolvendo conflitos ou certificando situações jurídicas”. (DIDIER JR., Fredie. Curso de Direito Processual Civil: introdução ao direito processual civil, parte geral e processo de conhecimento. 22. ed. Salvador: JusPODIVM, 2020, p. 208, grifo do autor).

$3 \quad$ Nesse sentido, Petrônio Calmon: "Mas não se pode deixar de ressaltar que a livre disposição de bens em face da autonomia em nada se relaciona com a exigência do devido processo legal, que somente se aplica à privação dos bens e não à liberdade que ocorre na autocomposição”. (CALMON, Petrônio. Fundamentos da mediação e da conciliação. Rio de Janeiro: Forense, 2013, p. 159). 
Com a devida vênia, essa posição parece partir de uma concepção muito restrita do devido processo legal. Com a evolução da compreensão do alcance dos direitos fundamentais, já se reconheceu até mesmo sua eficácia horizontal, pela qual eles incidem também nas relações privadas, de modo que, mesmo na conciliação e na mediação extrajudiciais, é possível falar em respeito ao devido processo legal. ${ }^{4}$

Com a incorporação mais profunda dos meios autocompositivos à realidade judicial, não é possível afastar por completo a incidência do princípio do devido processo legal. A via judicial passou a admitir de forma ampla a solução do conflito pela via jurisdicional e por meios autocompositivos. Nessa condição, a conciliação, a mediação e outras formas de gestão autocompositiva de conflitos são promovidas e controladas pelo Estado.

Portanto, tratando-se de uma solução de conflitos no âmbito do Poder Judiciário, com o acordo homologado pelo juiz e assumindo a condição de título executivo judicial, é necessário resguardar aos litigantes que chegam a uma autocomposição as garantias processuais com maior intensidade, para evitar vícios e abusos. ${ }^{5}$

Na tentativa de equalizar as peculiaridades das vias autocompositivas com as garantias do processo judicial, recorre-se à posição defendida por Richard Reuben (2000), para quem o devido processo legal manifestado na mediação judicial é o mínimo, mas significativo. ${ }^{6}$ Dessa forma, o procedimento adotado deve ser somente o indispensável para resguardar padrões necessários à preservação das diretrizes axiológicas de um processo constitucionalmente regular.

Isso implica, segundo o autor, assegurar o direito a um foro neutro e a um direito qualificado ao conselho. A ideia de foro neutro importa, em síntese, na definição de regras que respeitem a imparcialidade do mediador e a neutralidade do local da mediação. O direito qualificado ao conselho materializa-se com medidas que protegem as partes do desequilíbrio de poder e asseguram a presença de um advogado para orientar as partes.

Além das proteções destacadas pelo referido autor, é possível identificar outras garantias do devido processo legal que são compatíveis com a autocomposição judicial, como o contraditório, a isonomia, a boa-fé, a cooperação, a proporcionalidade, a efetividade, a razoável duração do processo, etc. Logicamente, a aplicação não se dá da mesma forma que no processo voltado para a decisão adjudicada. Mesmo entre os princípios compatíveis com a jurisdição e com a autocomposição, não haverá uma identidade de manifestação, pois a natureza não jurisdicional deve ser respeitada.

Por outro lado, é certo que uma série de garantias processuais se destinam exatamente a conduzir a atuação adequada por parte dojuiz na função de julgador.É o caso dos princípios da persuasão racional, do dever de fundamentação das decisões, da proibição de utilização de provas ilícitas na formação do convencimento do juiz, da publicidade, etc. Como na conciliação e na mediação o magistrado não assume a postura de julgador, essas garantias não são reclamadas de forma direta e imediata.

4 STF, RE 201.819/RJ, rel. min. Ellen Gracie, rel. p/ acórdão min. Gilmar Mendes, DJ 27/10/2006. STF; RE 158.215/ RS, rel. min. Marco Aurélio, DJ 7/6/1996.

5 Como observa Klever Paulo Leal Filpo: "o estranhamento deriva do fato de que a lógica que instrui a mediação, considerada em seu estado in natura, parece bem diferente da lógica que orienta o processo judicial. Por isso, para que ambos convivam em um mesmo ambiente e, mais ainda, para que dialoguem dentre de um mesmo processo, são necessários inevitáveis ajustes e adequações, mas de duvidosa efetividade. Assim, é preciso indagar e buscar compreender de que modo esse diálogo vem ocorrendo”. (FILPO, Klever Paulo Leal. Mediação judicial: discursos e práticas. Rio de Janeiro: MauadFaperj, 2016, p. 137).

6 A ideia de devido processo legal mínimo, mas significativo é manifestada por Richard Reuben: "Esses mínimos, mas significativos, padrões do devido processo legal incluem a garantia de um fórum neutro, a significativa oportunidade de apresentar e confrontar evidências e o direito qualificado a um advogado" (tradução nossa). No original: "Those minimal but meaning ful due process standards include the assurance of a neutral forum, the meaning ful opportunity to present and confront evidence, and the qualified right to counsel'. (REUBEN, Richard. Constitutional gravity: a unitary theory of alternative dispute resolution and public justice. UCLA Law Review, v. 47, p. 949-1104, 2000, p. 1055). 
O fato é que o devido processo legal está presente, mas se manifesta de forma diferente. A carga axiológica elevada e a manifestação multidimensional desse princípio constitucional permitem exteriorizações diferentes em realidades distintas.

Na tentativa de materializar as proteções relacionáveis ao devido processo legal que sejam aplicáveis aos meios de gestão consensual de conflitos, é possível utilizar alguns dos princípios informativos da conciliação e da mediação. Isso porque, ao se garantir um conciliador/mediador imparcial e independente, um procedimento confidencial, que assegure a isonomia, a autonomia privada, a boa-fé, a decisão informada e o respeito à ordem pública e às leis vigentes, consequentemente estarão sendo atendidos os valores que compõem o núcleo essencial do princípio do devido processo legal.

É preciso registrar que, embora essas garantias devam ser resguardadas mesmo nas autocomposições extrajudiciais, o nível de controle deve ser mais rígido no âmbito judicial diante da maior influência do controle estatal. Nesse contexto, o conciliador ou mediador ganha como atribuição adicional o dever de prezar as regras procedimentais que efetivam as garantias dos devido processo legal.

Daí a necessidade de regulamentação de alguns aspectos do processo de conciliação e de mediação, de modo a garantir que existam neles etapas realizadoras dos princípios e garantias do devido processo legal. No entanto, existe uma característica essencial que impede a adoção de um procedimento rígido e detalhado: a informalidade.

A flexibilidade procedimental é uma marca caracterizadora da autocomposição, responsável pela possibilidade de maior adequação às peculiaridades do conflito e das partes. Em função dessa informalidade, o devido processo legal não pode se manifestar da mesma forma e com a mesma intensidade nos meios autocompositivos e nos heterocompositivos.

Ademais, é preciso destacar que o estímulo à automoposição envolverá somente alguns atos do processo, de modo que, como tantos outros atos específicos, não atrai toda a carga principiológica do devido processo legal, mas apenas aqueles preceitos axiológicos diretamente relacionados com sua natureza.

Do ponto de vista procedimental, não se encontram impedimentos à assimilação, mesmo porque os princípios da adequação e da instrumentalidade das formas permitem ajustamentos procedimentais suficientes para acomodar a estrutura das sessões de conciliação ou de mediação na lógica processual.

De acordo com o princípio da adequação, é necessário compatibilizar o processo com as especificidades do caso concreto. O procedimento não pode ser considerado uma fôrma rígida que exija que a causa se amolde aos seus contornos, mas exatamente o contrário. Devem existir áreas de relativa maleabilidade procedimental para que as peculiaridades do caso concreto não entrem em conflito com o processamento da ação. Essa possibilidade de acomodação formal do processo enseja uma maior aproximação das normas gerais e abstratas aos limites concretos da demanda. ${ }^{7}$

Esse princípio se manifesta em três perspectivas complementares: a legislativa, a judicial e a convencional. Sem desconsiderar a importância das duas primeiras manifestações, merece destaque nesse ponto a adequação convencional. Por meio de negócios processuais as partes podem "estipular mudanças no procedimento para ajustá-lo às especificidades da causa e convencionar sobre os seus ônus, poderes, faculdades e deveres processuais" (art. 190 do CPC). Essa é uma das principais formas de adaptação do procedimento, pois atende aos interesses daqueles que efetivamente conhecem as

$7 \quad$ Esclarece Rosalina Freitas Martins de Sousa: "Como instrumentos oferecidos aos interessados para auxiliar na composição de litígios, os métodos obterão melhores resultados se servirem à solução daqueles conflitos cujas especificidades se ajustem, se adéquem, enfim, se identifiquem com o procedimento e com as técnicas de cada um deles. Dizer que um meio de resolução é o mais adequado é o mesmo que dizer que, dentre outros existentes, ele é o mais ajustado para resolver uma determinada situação”. (SOUSA, Rosalina Freitas Martins de. A função jurisdicional adequada e a releitura do princípio da inafastabilidade do controle jurisdicional (CRFB/88, art. 5., XXXV). 2017. Tese (Doutorado em Direito) - Universidade Federal de Pernambuco, Recife, 2017, p. 44). 
necessidades e os interesses que envolvem a lide. Trata-se de mais uma manifestação da autonomia privada no âmbito processual.

Nas vias autocompositivas, essa maleabilidade e adaptabilidade procedimental é potencializada para permitir o melhor desenvolvimento do diálogo entre as partes. Em um ambiente com menos amarras e formalidades, os litigantes que não são versados na técnica jurídica e nos protocolos legais sentem-se mais livres para a negociação. ${ }^{8}$

Esse ambiente contribui para a compreensão de que a adequação do processo à causa vai além da adaptação de prazos, da especificação de competências, do ajuste da complexidade procedimental, etc. ${ }^{9}$ Importa compreender que o mecanismo de solução também deve se ajustar às características do conflito e que, em determinados casos, os meios de heterocomposição não são os mais apropriados. ${ }^{10}$

Por fim, deve-se advertir que reconhecer a incidência do devido processo legal na conciliação e na mediação, ainda que de forma diferenciada, importa em consequências processuais quando violado, o que, em casos mais graves, pode justificar inclusive a invalidação dos acordos firmados quando houver violação de princípios que cause prejuízos às partes. Não se trata de autorização para a declaração de nulidade por vícios procedimentais e formais menos significativos. A informalidade desse sistema consensual de resolução de conflitos é indispensável ao seu funcionamento, portanto, somente quando restar caracterizado o prejuízo que atinja o conteúdo do acordo, deve a autocomposição ser considerada viciada. ${ }^{11}$

\section{Manifestação do Devido Processo Legal nos Princípios Informadores da Conciliação e Mediação Relacionados à Regularidade do Procedimento}

As principais garantias de regularidade das conciliações e mediações manifestam-se por meio de seus princípios informadores, de modo que, no âmbito judicial, alguns deles se conectam com a base axiológica do princípio do devido processo legal para assegurar higidez ao ato processual.

Não se discutirão teorias e correntes sobre a distinção estrutural das espécies normativas para avaliar criticamente se os preceitos normativos apontados pela legislação como princípios informativos da mediação expressam-se efetivamente por normas de cunho principiológico. O fato é que eles

8 Diogo Assumpção Rezende de Almeida afirma: "O sistema multiportas é a implementação efetiva do princípio da adequação, porquanto parte da premissa de que existem vantagens e desvantagens na utilização de cada um dos processos de solução de conflitos e, por conseguinte, oferece ao interessado as diversas opções existentes”. (ALMEIDA, Diogo Assumpção Rezende de. O princípio da adequação e os métodos de solução de conflitos. Revista de Processo, São Paulo, v. 36, n. 195, p. 185-208, maio 2011, p. 202).

9 Ensina Piero Calamandrei: “[...] o Código tem tratado de temperar a excessiva rigidez, adotando, no lugar de um tipo de procedimento único e invariável para todas as causas, um procedimento adaptável às circunstâncias, que pode ser, em caso de necessidade, abreviado ou modificado, podendo assumir múltiplas figuras, em correspondência com as exigências concretas de cada causa”. (CALAMANDREI, Piero. Direito Processual Civil: estudos sobre o processo civil. Tradução de Luiz Abezia e Sandra Drina Fernandez Barbery. Ciência do Processo, v. 1. Campinas: Bookseller, 1999, p. 299-300).

10 Segundo Kazuo Watanabe, "Quando se trata de solução adequada dos conflitos de interesses, insisto em que o preceito constitucional que assegura o acesso à Justiça traz implicitamente o princípio da adequação; não se assegura apenas o acesso à justiça, mas se assegura o acesso para obter uma solução adequada aos conflitos, solução tempestiva, que esteja bem adequada ao tipo de conflito que está sendo levado ao Judiciário". (WATANABE, Kazuo. Modalidade de mediação. In: DELGADO, José et al. (coord.). Mediação: um projeto inovador. Brasília, DF: Centro de Estudos Judiciários, 2003. p. 42-50, p. 49).

11 Ainda nas palavras de Richard Reuben: "Violações mínimas, porém significativas, do devido processo em sistemas informais de resolução de disputas, particularmente em sistemas consensuais como a mediação, devem ser reservadas para os mais notórios abusos, para levar em conta a flexibilidade necessária para permitir que esses processos funcionem. O devido processo é um escudo, não uma espada" (tradução nossa). No original: "Minimal but meaningful due process violations in informal systems of dispute resolution, particularly consensual systems like mediation, should be reserved for the most egregious of abuses, to allow for the flexibility necessary to permit those processes to work. Due process is a shield, not a sword". (REUBEN, Richard. Constitutional gravity: a unitary theory of alternative dispute resolution and public justice. p. 949-1104. UCLA Law Review, v. 47, 2000, p. 1094). 
apresentam diretrizes valorativas que permitem a definição do modo como devem ser realizadas as mediações.

A violação desses princípios pode acarretar a aplicação de sanção administrativa consistente na exclusão dos cadastros de mediadores e conciliadores, conforme dispõe o art. 173 do CPC. Embora o referido dispositivo faça referência a situações específicas, há entendimento de que o rol legal é meramente exemplificativo, abrangendo a violação a outras regras e princípios. ${ }^{12}$ Logicamente, a questão será tratada em sede de processo administrativo que assegure ao profissional o contraditório e a ampla defesa.

Como é comum no estudo das normas fundamentais de qualquer área do direito, também no âmbito da gestão consensual de conflitos não há um consenso quanto a um rol fixo de normas basilares que a orientam. Mesmo na legislação não há uma unanimidade na enumeração desses princípios. De modo a realizar uma abordagem mais ampla do tema, serão analisados os princípios presentes no CPC, na Lei de Mediação e na Resolução n.ํ 125/2010 do CNJ, ainda que constantes de um só desses instrumentos normativos.

Por esses três diplomas normativos são identificados quatorze princípios: a imparcialidade, a independência, a competência, a autonomia privada, a busca do consenso, o respeito à isonomia, a informalidade, a oralidade, a confidencialidade, a boa-fé, o empoderamento, a validação, a decisão informada e o respeito à ordem pública e às leis vigentes.

Analisando-os sob a perspectiva do devido processo legal, é possível dividir esses princípios em dois grupos. O primeiro deles relaciona-se à regularidade do procedimento, mantendo, assim, uma relação mais próxima com as garantias constitucionais do processo. São eles: a imparcialidade, a independência, a autonomia privada, a isonomia, a confidencialidade, a boa-fé, a decisão informada e o respeito à ordem pública e às leis vigentes.

Os demais princípios compõem o segundo grupo, relacionado à efetividade do estímulo à autocomposição. A competência, a busca do consenso, a informalidade, a oralidade, o empoderamento e a validação destinam-se a criar um ambiente mais propício à autocomposição. Sua violação ou seu não atendimento pleno não comprometerá necessariamente um acordo que venha a ser realizado ou acarretará consequências processuais específicas.

Passa-se a analisar cada um do princípios que compõem o primeiro grupo para melhor destacar sua amplitude e suas repercussões práticas.

\section{Imparcialidade do Mediador e do Conciliador}

O primeiro princípio que merece atenção é o da imparcialidade. Ele está previsto no artigo 166 do CPC, no artigo 2.․ I, da Lei de Mediação e no artigo 1.․․ IV, do anexo III da Resolução n.o 125/2010 do CNJ. A imparcialidade é uma das poucas qualidades exigidas dos mediadores e conciliadores que é aceita quase unanimemente como indispensável por todas as correntes doutrinárias que se dedicam ao tema. É ela que permite ao profissional manter uma equidistância entre as partes, viabilizando o estabelecimento de uma relação de confiança, necessária para fazer funcionar a gestão consensual do conflito.

O conceito de imparcialidade é bem conhecido no âmbito judicial, bastante estudado quanto à atuação dos magistrados de modo a evitar qualquer tipo de favorecimento no julgamento da causa. Toda essa compreensão pode ser aplicada aos mediadores e aos conciliadores, pois, em sua atuação,

12 Esse é o entendimento de Fernando Gajardoni: "O art. 173 do CPC/2015 enuncia um rol exemplificativo de hipótese de exclusão de mediadores / conciliadores judiciais”. (GAJARDONI, Fernando da Fonseca. Comentário ao art. 173. In: GAJARDONI, Fernando da Fonseca; DELlORE, Luiz; ROQUE, André Vasconcelos; OLIVEIRA JR., Zulmar Duarte de (coord.). Teoria geral do processo: comentários ao CPC de 2015. Rio de Janeiro: Forense, 2017, p. 555). 
não podem ter favoritismos, preferências, aversões ou preconceitos. ${ }^{13}$ Embora esses profissionais não possuam poder decisório, podem influenciar o processo de negociação, conduzindo as partes a uma decisão tendenciosa.

Por conseguinte, a imparcialidade é essencial tanto nos meios adjudicatórios como nos autocompositivos. Para atuar no processo, o profissional responsável pela sessão deve estar apto a fomentar o consenso sem qualquer tipo de interesse na solução dos conflitos. Embora não possua poder decisório, é inegável que o conciliador ou mediador pode interferir, ainda que indiretamente, na solução do conflito, de modo que não pode utilizar-se de sua posição para induzir as partes a nenhuma solução específica, não lhe cabendo realizar juízos de qualidade sobre o mérito do acordo.

Algumas técnicas da conciliação e da mediação requerem que o profissional que conduz a sessão expresse uma compreensão do conflito e dos interesses em jogo. Nesses casos, exige-se muita capacidade técnica e cautela para não externar aparentes favoritismos. Por exemplo, exige-se empatia para gerar um sentimento de confiança e de comprometimento, mas de modo idêntico com ambas as partes. Na validação de sentimentos, é preciso demonstrar que compreendeu a perspectiva das partes, sem, todavia, deixar transparecer que concorda com ela. No resumo, ele deve pesar de forma positiva os fatos apresentados pelas partes, sem indicar que uma parte está certa e a outra está errada.

O fato de o conciliador ou mediador não ser um tomador de decisão sobre o conflito diminui significativamente as preocupações relativas ao impacto de uma atuação parcial, quando comparado à potencialidade de dano de um julgador com a mesma condição. Isso não implica dizer que a existência de interesse no conflito não é um problema sério na autocomposição. Um profissional competente, mas tendencioso, pode influenciar e direcionar o acordo firmado pelas partes, distorcendo a utilização de técnicas para esse fim escuso.

Isso se revela particularmente grave, por exemplo, em situações em que há um desequilíbrio de poder entre as partes. É por essa razão que um dos deveres daquele que está conduzindo a sessão é tentar reduzir o desequilíbrio de poder tanto quanto possível, ou encerrar a sessão se o desnível não for superável. Um mediador parcial pode, ao contrário, explorar tal desequilíbrio em detrimento da parte mais fraca, disfarçando sua tendenciosidade ou simplesmente omitindo-se, quando deveria agir para preservar a isonomia ${ }^{14}$.

Essa preocupação fica ainda mais acentuada quando o mediador recorre a posturas mais incisivas, emitindo opiniões, destacando aspectos específicos da controvérsia que pesam a favor de uma das partes, etc. A apresentação de sugestões de solução para o litígio é a técnica que mais pode ser conduzida para influenciar os termos de um acordo mais benéfico para uma das partes. É esse o motivo de ser ela uma das técnicas mais complexas e arriscadas.

O Código de Processo Civil reconhece expressamente a aplicação dos motivos de impedimento e de suspeição aos auxiliares da justiça, dentre os quais se destacam os conciliadores e mediadores (art. 148, II, c/c art. 149).

Dessa forma, a parte que se sentir prejudicada antes, durante ou após a conclusão da sessão deve arguir o impedimento ou a suspeição requerendo o encerramento da sessão ou por meio de petição fundamentada e devidamente instruída. Uma vez demonstrada qualquer das hipóteses enumeradas nos artigos 144 e 145 do CPC, deve ser reconhecido o vício no acordo, desconstituindo-se o título executivo judicial eventualmente formado.

Vale destacar que para a recusa de um conciliador ou mediador não há a necessidade de configuração de impedimento ou de suspeição. A simples desconfiança ou o desconforto de uma das

13 Na definição de Christopher W. Moore, "A imparcialidade refere-se à ausência de tendenciosidade ou preferência em favor de um ou mais negociadores, de seus interesses ou das soluções específicas que eles estão defendendo. A neutralidade, por outro lado, refere-se ao relacionamento ou comportamento entre o interventor e os disputantes". (MOORE, Christopher W. O processo de mediação: estratégias práticas para a resolução de conflitos. 2. ed. Porto Alegre: Artmed, 1998, p. 55).

14 As formas de atuação de que dispõem o conciliador e o mediador para garantir a isonomia serão abordados no tópico específico a seguir. 
partes com a postura do profissional pode justificar a recusa, a qual pode ser feita antes ou no curso da sessão.

Diante dessas possibilidades, é aconselhável que o nome do profissional que conduzirá a sessão seja informado às partes com a maior brevidade possível, para, quando necessário, possibilitar sua substituição sem o adiamento da sessão. Também é oportuno que o profissional adote, como parte de sua declaração de abertura, a prática de informar as partes de sua imparcialidade, explicando que não se enquadra em qualquer das situações de impedimento ou suspeição descritas no Código, e de questionar se alguma delas conhece algum fator que possa indicar sua parcialidade.

Essa é uma forma de despertar a sensação de confiança das partes. Pela mesma razão, eventual contato anterior com uma das partes, mesmo não ensejando qualquer das hipóteses de impedimento ou suspeição, não deve ser ocultada. Ao contrário, deve ser informada e explicada para que as próprias partes analisem se o fato compromete sua confiança. ${ }^{15}$

Por mais que se sustente a menor interferência do conciliador e do mediador nos termos do acordo, diante da ausência de decisão por parte desse profissional, a questão deve ser analisada de forma objetiva. Não há que se condicionar a nulidade à comprovação de prejuízos, por exemplo. É difícil para a parte prejudicada comprovar que a conduta de um mediador ou conciliador tendencioso atingiu o nível de influência suficiente para interferir de forma efetiva na decisão das partes sobre o acordo, principalmente em função da confidencialidade do ato.

Em função dessa dificuldade, é imprescindível que se informe e se assegure às partes a ampla possibilidade para escolher o mediador ou conciliador, recusar um que tenha sido indicado ou pedir o encerramento da sessão a qualquer momento e sem nenhum prejuízo. Essas manifestações da voluntariedade representam medidas concretas de controle do ato pelos jurisdicionados, garantindolhes a sensação de controle e segurança na mediação judicial.

Analisando-se sob a perspectiva oposta, também é possível considerar que, no processo de escolha do conciliador ou mediador, exista um consenso entre os litigantes para admitir um profissional que se enquadre em alguma das hipóteses de suspeição, mas que, para as partes, esse fator não é decisivo para afastar a sua imparcialidade. ${ }^{16}$ Diante dessa manifestação expressa, a questão não poderá ser apresentada no futuro por violação ao dever de coerência (venire contra factum proprium). Nessa situação, não é cabível qualquer tipo de punição ao profissional, como a exclusão do cadastro previsto no artigo 173, II, do CPC. Por outro lado, se durante as sessões as partes sentirem-se incomodadas com a postura do mediador, também não haverá impedimento a que requeiram a substituição do conciliador ou do mediador ou a desistência da mediação.

Já no que concerne às hipóteses caracterizadoras de impedimento, o artigo 170 do CPC é taxativo em determinar de forma cogente que o mediador ou o conciliador comunique o fato e devolva o processo ao juiz da causa ou ao coordenador do Centro Judiciário de Solução Consensual de Conflitos (Cejusc) para que seja providenciada a nomeação de um novo profissional.

Se nenhuma das providências previstas for suficiente para evitar prejuízos decorrentes da parcialidade do conciliador ou do mediador e as partes celebrarem um acordo inadequado, será possível, em teses, a anulação da avença por esse motido.

15 Observam Delton Ricardo Soares Meirelles e Fernando Gama de Miranda Netto: “[...] cabe ao mediador esclarecer qualquer dúvida quanto a um eventual contato anterior com uma ou ambas as partes, consultando-as sobre a conveniência de tê-lo como agente da mediação". (MEIRELLES, Delton Ricardo Soares; MIRANDA NETTO; Fernando Gama de. Mediação judicial no projeto do novo Código de Processo Civil. Revista de Arbitragem e Mediação, São Paulo, v. 9, n. 33, p. 213-236, abr./ jun. 2012, p. 219).

16 É o que questiona Fernanda Tartuce: "que tal perguntar às partes se elas realmente veem tal impedimento como determinante para o afastamento do mediador? Essa checagem é consentânea com a autonomia da vontade e configura a postura adotada em arbitragens em que são deflagradas constatações de anteriores atuações advocatícias, por exemplo. Em muitos casos as partes podem não se sentir afetadas por conta de fatores como a antiguidade da ocorrência, a confiança na honestidade da pessoa nomeada e a imparcialidade demonstrada nas abordagens até entre empreendidas”. (TARTUCE, Fernanda. Mediação nos conflitos civis. 2. ed. São Paulo: Método, 2015, p. 203). 


\section{Independência}

A independência, prevista no artigo 166 do CPC e no artigo 1. ${ }^{\circ}, \mathrm{V}$, do anexo III da Resolução n. ${ }^{\circ}$ 125/2010 do CNJ, relaciona-se à garantia de autonomia do mediador e do conciliador na condução da sessão de mediação ou de conciliação no estrito limite dos interesses dos litigantes. ${ }^{17}$ Se relaciona com a ideia de imparcialidade, porém, estando dirigido a interferência indevidas na atuação do profissional e não propriamente de uma preferência destes.

Não pode haver ingerência da administração do Poder Judiciário, do coordenador do Centro Judiciário de Solução Consensual de Conflitos ou do juiz da causa na atuação do conciliador ou do mediador tendente a induzir resultados específicos nas sessões. Esse tema foi debatido durante a tramitação do Projeto do CPC, reconhecendo-se, ao final, a importância da independência do mediador e do conciliador. ${ }^{18}$

A remessa dos autos aos Cejusc é uma forma de aumentar a sensação de independência, pois garante certo distanciamento dos olhares do juiz da causa, reduzindo a chance de orientações, ainda que veladas ou subliminares, e o receio de controle da atuação por parte dos próprios mediadores e conciliadores.

É válido lembrar que, em grande parte dos casos, os juízes coordenadores dos Cejusc cumulam essa função com a atividade jurisdicional, sendo sua unidade uma das que encaminham processos ao Centro. Nesses casos, o juiz da causa mantém uma proximidade com o processo, mesmo estando os autos no Cejusc. É por essa razão que a remessa do processo para câmaras privadas credenciadas no Poder Judiciário representa uma das melhores formas de garantir a independência dos mediadores.

Também em razão da independência, o conciliador ou mediador não pode estar submetido a certas metas de produtividade, por exemplo, com a indicação de um percentual de acordos que devam ser alcançados por sessões realizadas. Ele deve atuar com liberdade, sem qualquer pressão por resultado ou dever de redigir acordo inexequível. O compromisso do profissional deve ser com a qualidade da gestão do conflito, coincidindo com a do Poder Judiciário nesse aspecto, ainda que lá também possa ocorrer algum tipo de violação.

Por outro lado, a independência não impede que se mantenha um controle de qualidade na atuação do mediador ou do conciliador. Esse acompanhamento presta-se a garantir a observância dos deveres funcionais, como a confidencialidade, a imparcialidade, a proibição de constrangimento, etc. Em tais situações, mediante procedimento que garanta o contraditório e a ampla defesa, é possível aplicar sanções ao profissional com advertência, suspensão, exclusão do cadastro ou condicionar sua atuação à reciclagem. Nada disso implica quebra da autonomia na condução da mediação ou da conciliação.

Outra questão que merece referência no estudo da independência é a submissão do acordo firmado pelas partes à homologação judicial. A análise do acordo pelo juiz terá como foco a regularidade do mérito do que foi estabelecido pelas partes, aspecto que não cabe ao conciliador ou ao mediador. ${ }^{19}$

17 Sobre a questão, ressalta Ravi Peixoto: "A independência do mediador e do conciliador tem por objetivo permitir que ele possa gerir as audiências e sessões sem sofrer pressões de qualquer ordem, sejam internas ou externas, não devendo, por exemplo, o juiz se intrometer no exercício de sua função". (PEIXOTO, Ravi. Os "princípios” da mediação e da conciliação. In: ZANETI JR., Hermes; CABRAL, Trícia Navarro Xavier (coord.). Justiça multiportas: mediação, conciliação, arbitragem e outros meios de solução adequada de conflitos. Salvador: JusPODIVM, 2016. p. 91-108, p. 96).

18 O Projeto do Código de Processo Civil (PLS 166/2010), em sua redação originária, previa norma em sentido diametralmente oposto. De acordo com a redação do então artigo 333, § 1.o "O juiz determinará a forma de atuação do mediador ou do conciliador, onde houver, observando o que dispõe a lei de organização judiciária”.

19 Nesse sentido, afirmam Ana Carolina Squadri Santanna, Cristina Vianna Veras e Giselle Picorelli Marques: "Destaque-se que o acordo é uma construção das partes e que a independência do mediador não se relaciona com o resultado, mas com o método e a prática da mediação. [...] A exigência de homologação subordina a autonomia e a independência das partes à análise do juiz, não a independência do mediador em si”. (SANTANNA, Ana Carolina Squadri; VERAS, Cristina Vianna; MARQUES, Giselle Picorelli Yacoub. Independência e imparcialidade: princípios fundamentais da mediação. In: ALMEIDA, Diogo Assumpção Rezende de; PANTOJA, Fernanda Medina; PELAJO, Samantha (coord.). A mediação no Novo Código de Processo Civil. 2. ed. Rio de Janeiro: Forense, 2016. p. 121-138, p. 130). 
Eventualmente, podem ser observadas irregularidades que comprometam a higidez do procedimento com reflexos em vícios de vontade, circunstância que pode afetar a validade do acordo. Nenhuma dessas questões compromete a autonomia do conciliador ou do mediador, pois, como já foi explicado, a independência relaciona-se à atuação e não ao resultado de um acordo a que eventualmente as partes possam chegar.

O mediador e o conciliador devem estar cientes da impossibilidade de intervenção em sua atuação. De modo que, caso sinta sua independência ameaçada ou violada, é-lhe permitido recusar a indicação, suspender ou interromper a sessão já iniciada, sem que esse fato possa ser imputado como irregular pelos órgãos de gestão da unidade judicial. Portanto, o mediador e o conciliador têm o dever de salvaguardar a independência inerente à sua função.

A violação desse princípio, quando a interferência tenha implicado em uma atuação inadequada do mediador ou do conciliador com prejuízo para o acordo firmado, pode acarretar a nulidade do acordo por retratar uma quebra da imparcialidade tanto quanto nas hipóteses tratadas no item anterior, a diferença está unicamente na origem dessa parcialidade.

\section{Autonomia Privada}

O artigo 166 do CPC, o artigo 2.. , V, da Lei de Mediação e o artigo 2.ำ, II, do anexo III da Resolução n.o 125/2010 do CNJ fazem referência ao princípio da autonomia da vontade. Sem preciosismo terminológico, registra-se que seria mais técnico utilizar a expressão "autonomia privada", uma vez que a vontade manifestada na autogestão e no autoregramento da vontade precisa estar em consonância com a ordem jurídica para ser juridicamente exigível. ${ }^{20}$ No entanto, no contexto da legislação as expressões são tratadas indistintamente como sinônimas.

De acordo com esse princípio, as deliberações das partes envolvidas nos conflitos devem ser soberanas, de modo que, no âmbito da conciliação e da mediação, são os litigantes que decidem qual a melhor solução para o conflito. O conciliador ou mediador atua somente como facilitador do diálogo, sem qualquer interferência na definição da solução. ${ }^{21}$

A lei não detalhou os efeitos principais desse princípio, como fizeram outros ordenamentos, como, por exemplo, o português. ${ }^{22}$ Ainda assim, é possível compreender e sustentar com firmeza que entre suas premissas essenciais estão: I) a necessidade de consentimento esclarecido e informado das partes para a realização da autocomposição; II) o direito de se retirar da sessão em qualquer momento, por decisão conjunta ou unilateral; III) o direito de escolher o mediador e; VI) a liberdade para definir a solução do conflito.

Como já mencionado anteriormente, é da autonomia privada que se extrai uma das principais ferramentas contra eventuais vícios e abusos na mediação e na conciliação, qual seja, o direito de interromper a sessão a qualquer momento, sem punição.

Ao propor uma demanda judicial, os litigantes delegam ao juiz o poder de decidir a causa nos termos preconizados pelo ordenamento jurídico. Porém, ao se optar por um meio de gestão consensual

20 RAATZ, Igor. Autonomia privada e processo: liberdade, negócios jurídicos processuais e flexibilização procedimental. 2a edição. Salvador: Juspodivm, 2019, p. 162. No mesmo sentido: CABRAL, Érico de Pina. A “autonomia” no direito privado. Revista de Direito Privado, São Paulo, v. 19, n. 5, p. 83-129, jul./set. 2004, p. 111.

21 Observa Lília Maia de Morais Sales: “as partes é que decidirão todos os aspectos do problema sem intervenção do mediador, no sentido de induzir as respostas ou as decisões, mantendo a autonomia e o controle das decisões relacionadas ao conflito. O mediador facilita a comunicação, estimula o diálogo, auxilia na resolução dos conflitos, mas não os decide”. (SALES, Lília Maia de Morais. Justiça e mediação de conflitos. Belo Horizonte: Del Rey, 2003, p. 50).

22 Lei Portuguesa n. 29 / 2013: “Artigo 4. Princípio da voluntariedade. 1 - O procedimento de mediação é voluntário, sendo necessário obter o consentimento esclarecido e informado das partes para a realização da mediação, cabendo-lhes a responsabilidade pelas decisões tomadas no decurso do procedimento. 2 - Durante o procedimento de mediação, as partes podem, em qualquer momento, conjunta ou unilateralmente, revogar o seu consentimento para a participação no referido procedimento. 3 - A recusa das partes em iniciar ou prosseguir o procedimento de mediação não consubstancia violação do dever de cooperação nos termos previstos no Código de Processo Civil”. 
de conflitos no processo, esse poder é retomado pelas partes, ocasião em que a disponibilidade do direito amplia as possibilidades, atuando a lei somente como moldura da margem de negociação. Em síntese, ao passo que o juiz tem de decidir de acordo com o que a lei determina, as partes podem decidir até onde a lei não próíbe.

No exercício da mediação e da conciliação, é necessário que os diferentes pensamentos dos envolvidos sejam respeitados, para garantir a construção de uma solução voluntária, na qual esteja assegurado o poder de decisão e o consentimento genuíno das partes. Não se admite qualquer tipo de pressão, constrangimento, ameaça, intimidação ou coerção, explícita ou velada, manifestada pela parte adversa, pelo mediador, conciliador ou por qualquer outro que esteja presente na sessão ou atuando nos bastidores.

Logo, a autonomia privada pressupõe a ausência de vícios de liberdade e de capacidade. Nessa condição, não se admite, por exemplo, a autocomposição celebrada por menores, ainda que eles possam eventualmente participar de fases da sessão para, respeitado seu estágio de desenvolvimento e grau de compreensão, ajudar a definir seus interesses ou direitos. ${ }^{23}$

Um dos vícios de postura dos mediadores e conciliadores em agressão à autonomia privada das partes é a utilização da aplicação subsidiária da jurisdição como ferramenta de pressão para a celebração de acordos. Os custos, o tempo e a substitutividade da jurisdição não podem ser ressaltados às partes para criar nelas um sentimento de aversão, com o intuito de instigá-las a uma solução consensual. A via jurisdicional é a adequada para a solução do conflito quando não há consenso das partes. Ela não é e não pode ser apresentada como sanção para a não realização de acordos.

Em último grau, a violação ao princípio da autonomia privada pode acarretar um vício de vontade por coação no acordo celebrado, uma vez que sua vontade interna não corresponde com a vontade manifestada em função da pressão injusta exercida sobre a parte. Essa é uma causa de anulabilidade do negócio jurídico (art. 171, II, do CC/2002), mas para tanto, há de ser tal que incuta ao paciente fundado temor de dano iminente e considerável à sua pessoa, à sua família, ou aos seus bens (art. 151 do $\mathrm{CC} / 2002)$.

\section{Isonomia}

O princípio da isonomia está previsto expressamente no artigo 2.․․ II, da Lei de Mediação e pode ser extraída do art. 7ํ do CPC em relação à autocomposição promovida judicialmente. Sem dúvida, um dos desdobramentos práticos mais relevantes do dever de respeito à isonomia nas sessões de mediação é a garantia de equilíbrio de forças entre as partes.

A atenção especial dada à isonomia nos meios consensuais de solução de conflitos decorre da informalidade procedimental que vigora neles. A ausência de salvaguardas processuais na conciliação e na mediação, similares àquelas estruturadas para a via adjudicatória, é particularmente preocupante à luz da dificuldade que o processo de mediação tem em lidar com os desequilíbrios de poder constatados entre os litigantes. O rito do processo judicial é uma forma de equilibrar o campo de jogo. A informalidade pode ter exatamente o efeito oposto e pode realmente exacerbar desequilíbrios de poder existentes. ${ }^{24}$

23 Enunciado n.o 26 da I Jornada de Prevenção e Solução Extrajudicial de Litígios do CJF: "É admissível, no procedimento de mediação, em casos de fundamentada necessidade, a participação de crianças, adolescentes e jovens respeitado seu estágio de desenvolvimento e grau de compreensão - quando o conflito (ou parte dele) estiver relacionado aos seus interesses ou direitos".

24 Assim, Adverte Mariana Hernandez Crespo: "Em teoria, se o terreno da contenda está nivelado, ou seja, se as partes têm recursos, capacidade e poderes iguais, então os métodos alternativos podem ser realmente um verdadeiro elemento de transformação. A realidade, entretanto, é bem diferente da teoria. Embora alguns estudiosos tenham sustentado que a mediação pode ampliar o acesso à justiça, ela não é o fórum para a proteção de direitos. A mediação se destina à negociação de interesses, e não à confirmação de direitos, e não existe nesse processo nenhum juiz que possa confirmar os direitos das pessoas destituídas de poder”. (CRESPO, Mariana Hernandez. Perspectiva sistêmica dos métodos alternativos de resolução de conflitos na América Latina: aprimorando a sombra da lei através da participação do cidadão In: ALMEIDA, Rafael Alves 
Caso não seja garantida a isonomia, há o risco de que um litigante ceda à pressão imposta pelo outro, dando ensejo a acordos excessivamente onerosos e em dissonância com os reais interesses de uma das partes. ${ }^{25} \mathrm{O}$ processo de mediação e de conciliação não dispõe de garantias formais que permitam a proteção de direito, apresentando-se como cenário arriscado em caso de diferença elevadas de recursos, capacidade e poderes entre os envolvidos.

Observe-se que a existência de desigualdades entre os litigantes é uma situação normal. As pessoas são diferentes e, portanto, as diferenças econômicas, de postura, de estratégia, entre outras, sempre estarão presentes. Isso não é problema para que se busque a autocomposição, desde que as variações se manifestem em níveis aceitáveis que não interfiram na capacidade de negociação. Isso não significa que o patrão não possa negociar com o empregado ou que uma empresa não possa negociar com o consumidor, por exemplo. Só quando as divergências forem desproporcionais e indicarem que acarretarão vícios no acordo é que a quebra do dever de isonomia está presente.

Exige-se do conciliador ou do mediador atenção às posturas das partes para identificar desequilíbrios significativos que possam comprometer a equivalência de autonomia negocial. Em caso de prosseguimento da sessão em uma situação de desigualdade substancial de forças, há uma tendência para que essa condição seja exaltada, o que acarreta uma solução para o conflito praticamente imposta pela parte que se sobrepõe. ${ }^{26}$ Acordos firmados nessas condições extremas podem ser anulados quando ficar demonstrada a quebra de isonomia em um nível que retrate verdadeiro vício de vontade na celebração do acordo.

Ressalte-se que não é fácil definir a forma de intervenção para auxiliar no restabelecimento da isonomia, pois o dever de imparcialidade impede que o conciliador ou mediador seja o "fiel da balança". Esses profissionais não podem auxiliar uma das partes, mesmo que por meio de orientações, pois tais práticas podem violar o dever de imparcialidade. Vale destacar que "aconselhar alguma das partes acerca do objeto da causa" é uma das ações que acarretam a sua suspeição (arts. 145, II, c/c 148, II, do CPC).

Uma possibilidade para o conciliador ou mediador em casos de aparentes desequilíbrios de baixa intensidade é a suspensão da sessão com a indicação de que os litigantes obtenham, organizem e analisem com maior profundidade os elementos do conflito e com isso planejem melhor sua atuação na negociação para um encontro posterior. ${ }^{27}$

A presença dos advogados é uma importante ferramenta para equalizar eventuais desproporções de forças, ou mesmo para auxiliar na percepção da quebra de isonomia. Nesse ponto, também assume grande importância a presença de acompanhantes - familiares ou amigos - trazidos pelas partes para

de; ALMEIDA, Tania; CRESPO, Mariana Hernandez (org.). Tribunal multiportas: investindo no capital social para maximizar o sistema de solução de conflitos no Brasil. Rio de Janeiro: FGV, 2012. p. 39-86, p. 60-61).

25 Pondera Daniel Amorim Assumpção Neves: "Por outro lado, em especial em determinadas áreas do direito material, como o direito consumerista, a distância econômica entre o litigante contumaz (fornecedor) e o litigante eventual (consumidor) gera transações - ou conciliações a depender do sentido emprestado ao termo - absolutamente injustas e que passam longe da tão propalada pacificação social. Se parece interessante por variadas razões para o fornecedor, para o consumidor a transação é muitas vezes um ato de necessidade, e não de vontade, de forma que esperar que ele fique satisfeito pela solução do conflito é de uma ingenuidade e, pior, de uma ausência de análise empírica preocupantes”. (NEVES, Daniel Amorim Assumpção. Manual de direito processual civil: volume único. 8. ed. Salvador: JusPodivm, 2016, p. 9).

26 Advertem Robert A. Bush e Joseph Folger: "Se e quando tal insatisfação for expressa, o mediador ajuda o disputante a esclarecer exatamente o que deseja, a transmitir o que deseja expressar à outra parte e a tomar as decisões que têm de enfrentar. No entanto, se uma parte aparentemente fraca não dá sinais de necessidade quando parece ser dominada por um disputante mais forte, se o mediador enfatiza a questão do desequilíbrio, isso substituirá o julgamento da parte pelo seu, passando a assumir um papel de interventor extremamente direcionador que é inconsistente com a abordagem transformativa”. (BUSH, Robert A. Baruch; FOLGER, Joseph P. Mediação transformativa e intervenção de terceiros: as marcas registradas de um profissional transformador. In: SCHNITMAN, Dora Fried; LITTLEJOHN, Stephen. Novos paradigmas em mediação. Porto Alegre: ArtMed, 1999. p. 85-100, p. 99).

27 Enunciado n. 34 da I Jornada de Prevenção e Solução Extrajudicial de Litígios do CJF: "Se constatar a configuração de uma notória situação de desequilíbrio entre as partes, o mediador deve alertar sobre a importância de que ambas obtenham, organizem e analisem dados, estimulando-as a planejarem uma eficiente atuação na negociação". 
a sessão. Trata-se de um reforço eficiente para as manifestações das partes e para a compreensão das questões debatidas.

Não obstante, na maioria das vezes, constatado o desequilíbrio de forças que inviabilize a negociação e que não pode ser superado por técnicas ou pelo suporte de terceiros, não resta outra saída senão a de encerrar a sessão, pela impossibilidade de alcançar uma solução consensual legítima para o conflito, conduzindo o caso à apreciação jurisdicional.

Outra faceta desse princípio refere-se a uma manifestação do contraditório e da ampla defesa. Tais garantias processuais são asseguradas pela ampla possibilidade de manifestação argumentativa pelos envolvidos no conflito de modo a possibilitar que ambas as partes se posicionem sobre cada aspecto novo que seja trazido à mesa de negociação por meio de um diálogo aberto, participativo e transparente. ${ }^{28}$ Dessa forma, as sessões de mediação e de conciliação representam o ambiente mais propício à efetivação dos valores conduzidos pelas garantias constitucionais do contraditório e da ampla defesa, realizando-os muito além de seu prisma formal.

Isso não implica a necessidade de um controle cronométrico do tempo de fala das partes; o importante é a ausência de obstáculos à sua manifestação. Sempre que houver necessidade de manifestação, de acordo com as regras definidas pelas partes, deve ser viabilizada sua fala após a conclusão da outra. Dessa forma, a sessão deve estender-se ou ser marcado um segundo encontro, se ainda houver necessidade de garantir a manifestação de uma das partes.

\section{Confidencialidade}

O princípio da confidencialidade está previsto no artigo 166 do CPC, no artigo 2.․, VII, da Lei de Mediação e no artigo 1., I, do anexo III da Resolução n.o 125/2010 do CNJ. Essa diretriz axiológica essencial da gestão consensual de conflitos resguarda o sigilo das informações produzidas no curso do procedimento.

A consciência do sigilo favorece o diálogo entre os litigantes. A segurança de que o conteúdo dos debates não ultrapassará as paredes da sala de sessões permite que as partes se afastem, em maior ou menor grau, das estratégias postulatórias, as quais, muitas vezes, conduzem à retenção de informações. A própria Lei de mediação, em seu artigo 14, aponta que o mediador deve alertar as partes sobre a confidencialidade.

A confidencialidade é uma condição para que as partes façam confissões parciais, apresentem propostas focadas em interesses mediatos que não constam expressamente dos autos, revelem fatos omitidos nas petições, etc. ${ }^{29}$ Enfim, esse princípio beneficia a manifestação da lide sociológica, propiciando um cenário mais rico para as negociações.

A interpretação do dever de sigilo deve ser extensiva, de modo a compreender todos os fatos, dados, manifestações, elementos e opiniões apresentados ou ocorridos durante os diálogos e negociações que envolvem a mediação.

Em razão do sigilo, os mediadores ou conciliadores e os membros de suas equipes ficam proibidos de divulgar as informações, por qualquer meio ou para qualquer finalidade, e de prestar depoimento testemunhal sobre elas (art. 166, \$§ 1. e 2.․ do CPC). Entende-se que esse dever proíbe a divulgação das informações inclusive ao magistrado. Portanto, ainda que o mediador esteja, de alguma forma,

28 Observa Petrônio Calmon: "O contraditório, visto por um ângulo mais amadurecido, não é somente um sistema formal de direitos e deveres, mas sim um sistema de transparência e diálogo, atributos mais presentes nos mecanismos para a obtenção da autocomposição do que no processo judicial. Ampla defesa nos mecanismos para a obtenção da autocomposição é participação muito mais do que apresentação de provas, argumentos e recursos". (CALMON, Petrônio. Fundamentos da mediação e da conciliação. Rio de Janeiro: Forense, 2013, p. 155).

29 Assim ressalta Antoine Youssef Kamel: "A confissão de fatos no ambiente da mediação, mesmo controvertidos em processo judicial, não pode ser relatada com outras pessoas, muito menos no próprio processo judicial no âmbito em que se realiza a mediação. Nem mesmo as propostas ou aceitações propostas podem ser referidas posteriormente”. (KAMEL, Antoine Youssef. Mediação e arbitragem. Curitiba: InterSaberes, 2017, p. 98). 
vinculado ao juiz responsável pelo caso, deverá atender a confidencialidade não lhe transmitindo informações abrangidas pelo sigilo. ${ }^{30}$

Como se percebe a violação ao princípio da confidencialidade não acarreta a nulidade de um acordo firmado. As consequências estão relacionadas a admissibilidade de determinadas provas em uma eventual instrução quando não houver autocomposição. Também pode acarretar a aplicação de multas que tenham sido previamente firmadas a esse respeito.

Em regra, exatamente para resguardar a confidencialidade, o acesso à sala das sessões deve ser restrito. Porém, com a autorização das partes, é possível que também ingressem no local da sessão outras pessoas com a finalidade de, por exemplo, dar suporte às partes ou para a formação acadêmica ou técnica. Embora não possam ser enquadradas como parte da equipe, aplicam-se a elas todas as restrições anteriormente mencionadas. Para tanto, é aconselhável que se registrem no termo da sessão todos os que ali se fizeram presentes.

A proibição da atuação do juiz como conciliador ou mediador nas ações que serão por ele julgada caso não haja acordo pode ser compreendida como um desdobramento lógico da confidencialidade. Ora, se o conciliador ou mediador não pode sequer testemunhar, trazendo elementos para a formação do convencimento do magistrado, menos ainda poderia o próprio magistrado atuar em tal condição, quando teria acesso direto às informações consideradas sigilosas.

Tratando-se de uma mediação judicial, impõe-se analisar a forma de interação desse princípio com o da publicidade dos atos processuais. Em perspectiva geral, esses princípios orientam caminhos opostos, porém, isso não implica em uma antinomia de normas, mas apenas em uma exceção a regra. Não há dúvida quanto à autorização constitucional para restrição da publicidade com o fim de preservar o direito à intimidade, limite no qual pode ser incluída a mediação (art. 93, IX, da CF/88). ${ }^{31}$

Apesar da relevância dessa garantia, é preciso ter em mente que a confidencialidade na conciliação e na mediação não é absoluta, pois não se refere às próprias partes do conflito. Dessa forma, diante da possibilidade de não haver acordo e dentro da estratégia postulatória, pode ser mais aconselhável que uma parte não divulgue questões que possam ser utilizadas em seu detrimento fora da mediação.

Assim, embora a confidencialidade impeça a divulgação das declarações feitas durante a mediação, não havendo prova escrita ou testemunhal que se possa tirar da sessão por expressa vedação do art. 30, $2^{\circ}$ da Lei de Mediação, a realidade é que as informações antes só conhecidas por uma das partes agora ficarão reveladas à parte adversa, expondo os pontos fortes e fracos da pretensão de uma das partes. A partir dessa informação, antes desconhecida, o advogado poderá buscar elementos probatórios para os fatos específicos que foram revelados. Esse é mais um motivo pelo qual a mediação não pode ser compulsória.

É importante destacar que a confidencialidade não impede o registro de todos os acontecimentos da sessão, mas somente aqueles relacionados à matéria do conflito. Assim, questões procedimentais podem e devem ser registradas se as partes o requererem.

$\mathrm{O}$ art. 30 da Lei de mediação excepciona a confidencialidade. O caput do artigo apresenta como três primeiras hipóteses de flexibilização a decisão expressa das partes expressamente, a exigência legal ou necessidade para cumprimento de acordo. Os $§ \S 3^{-0}$ e $4^{\underline{o}}$ do referido dispositivo dispõe que

30 Enunciado n.o 46 da I Jornada de Prevenção e Solução Extrajudicial de Litígios do CJF: "Os mediadores e conciliadores devem respeitar os padrões éticos de confidencialidade na mediação e conciliação, não levando aos magistrados dos seus respectivos feitos o conteúdo das sessões, com exceção dos termos de acordo, adesão, desistência e solicitação de encaminhamentos, para fins de ofícios".

31 Como observam Marina Beatriz Pereira Corrêa e Raquel Helena Duarte Cordeiro: "O princípio da confidencialidade pode se mostrar favorável a mediação, mas aparentemente pode vir a esbarrar no princípio da publicidade. Contudo, a luz do art. 5º, LX da Constituição Federal, torna-se possível notar que a confidencialidade é um fator limitante à publicidade quando para a defesa da intimidade ou interesse social." (CORRÊA, Marina Beatriz Pereira e CORDEIRO, Raquel Helena Duarte. Os princípios orientadores da mediação no novo Código de Processo Civil e as garantias constitucionais. In: PINHO, Humberto Dalla Bernardina; SANTANNA, Ana Carolina Squadri; SOBREIRA, Eneisa Miranda Bittencourt; PAUMGARTTEN, Michele Pedrosa. (org.). Mediação judicial e garantias constitucionais. Niterói RJ: PPGSD, 2013. p. 76-87, p. 84). 
também não estão cobertos pela confidencialidade a ocorrência de crime de ação pública e informações à administração tributária.

É importante informar tais exceções para as partes, quando da declaração de abertura, para que possam dosar suas manifestações com segurança da real extensão da confidencialidade da sessão.

\section{Boa-Fé}

O princípio da boa-fé encontra amparo no artigo 2.․, VIII, da Lei de Mediação e consta como norma fundamental do processo no artigo 5.. do CPC. De acordo com esse princípio, aqueles que, de qualquer forma, participem da mediação ou da conciliação devem agir com honestidade, lisura e sinceridade.

Embora se espere da sessão destinada a promover a autocomposição das partes um ambiente cooperativo, tomado por uma atmosfera de pacificação, no qual os litigantes se encontram com o espírito desarmado e em busca de um consenso, a realidade pode ser o oposto. É plenamente possível que alguns litigantes, sem qualquer propósito de acordo, utilizem-se da audiência destinada à composição com finalidades diversas. Eles podem buscar na sessão uma oportunidade de conhecer antecipadamente estratégias postulatórias da parte adversa, de pressioná-la a abdicar total ou parcialmente da pretensão, de retardar o julgamento da causa, etc.

O princípio da boa-fé veda a deturpação dessas técnicas para atingir finalidades diversas daquelas às quais se destinam, a criação de posições desvantajosas para a parte adversa, a adoção de medidas contraditórias etc. A constatação de ações que contrariam esse princípio pode acarretar a interrupção antecipada da sessão pelas partes ou pelo conciliador ou mediador e até mesmo a aplicação de multa por litigância de má-fé.

É preciso lembrar que existem elementos normativos para avaliar de forma objetiva a violação da boa-fé, evitando que a discussão se perca em questões de cunho subjetivo. Dentre as condutas descritas como configuradoras da litigância de má-fé que podem relacionar-se com posturas desleais na mediação, destacam-se as mencionadas nos incisos IV e V do artigo 80 do CPC, que tratam, respectivamente, da oposição de resistência injustificada ao andamento do processo e da conduta temerária em qualquer incidente ou ato do processo. Nesses casos, é cabível a aplicação de multa processual para punir o litigante de má-fé.

\section{Decisão Informada}

O princípio da decisão informada está previsto no artigo 166 do CPC e no artigo 1.․․, II, do anexo III da Resolução n. - 125/2010 do CNJ. De acordo com ele, as partes devem ser mantidas plenamente informadas quanto aos seus direitos e ao contexto fático no qual estão inseridas, abrangendo as etapas preparatórias, técnicas e negociações e, em especial, o acordo eventualmente celebrado. ${ }^{32}$

No que concerne ao dever de informação sobre os direitos das partes, cabe salientar que ao conciliador e ao mediador não compete a função de assessoramento jurídico dos litigantes, tanto que dele não se exige nem sequer formação jurídica. Cabe a esses profissionais tão somente se certificar de que as partes estão compreendendo os impactos das decisões tomadas, advertindo-as da necessidade de aconselhamento com um advogado, se for o caso.

\footnotetext{
32 Fernando Gama de Miranda Netto e Irineu Carvalho de Oliveira Soares destacam: "A sua aplicação procura evitar que as partes sejam surpreendidas, e compreende todas as etapas da mediação e até mesmo os contratos que precederam o processo. Esse princípio abomina qualquer omissão ou supressão de informações necessárias ao entendimento de algum detalhe sobre o procedimento, o objeto mediado e as consequências de um possível acordo". (MIRANDA NETTO; Fernando Gama de; SOARES; Irineu Carvalho de Oliveira. Princípios procedimentais da mediação no Novo Código de Processo Civil. In: ALMEIDA, Diogo Assumpção Rezende de; PANTOJA, Fernanda Medina; PELAJO, Samantha (coord.). A mediação no Novo Código de Processo Civil. 2. ed. Rio de Janeiro: Forense, 2016. p. 109-120, p. 113).
} 
Embora o sentido da decisão judicial a ser proferida em caso de ausência de autocomposição não seja algo objetivamente mensurável, uma noção razoável da probabilidade de sucesso da pretensão no processo é um fator importante na análise de informação sobre o direito. No entanto, aceitar um acordo em sentido diverso do que provavelmente decorreria da decisão adjudicada não reflete um vício.

Diversos fatores podem pesar para a aceitação do acordo, como a valorização de questões e ações sem repercussão patrimonial, o tempo até o julgamento definitivo e a resistência do devedor à atividade executória.

A questão aqui está relacionada também à plena compreensão do sentido de sua decisão. Dessa forma, a violação desse princípio pode manifestar um vícios da vontade (erro, dolo, coação, estado de perigo e lesão) ou de vícios sociais (fraude contra credores e simulação), que são causas de anulabilidade do negócio jurídico, nos termos do art. 171, II, do CC/2002. O mais provável é que o possível vício esteja relacionado a erro ou dolo. Assim, seja por desconhecimento acerca de determinado objeto por indução de outra parte a sua concordância não decorreu de sua efetiva vontade.

Na perspectiva da informação sobre o contexto fático do conflito, destaca-se a exequibilidade do acordo. Nesse ponto, assume grande relevância a confirmação com as partes das consequências práticas do acordo, inclusive com uma projeção da operacionalização do cumprimento da decisão, levando-as a avaliar sua exequibilidade, como forma de evitar a celebração de acordos desassociados da vontade efetivamente existente.

\section{Respeito à Ordem Pública e às Leis Vigentes}

Por derradeiro, o princípio do respeito à ordem pública e às leis vigentes consta do artigo 1.,

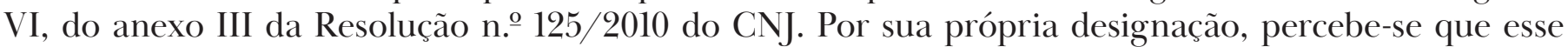
princípio objetiva estabelecer limites à condução e ao resultado da autocomposição.

Nos termos de sua definição, destaca-se a expressão "ordem pública”, que é um conceito jurídico indeterminado, com alto grau de abstração e generalidade. A melhor forma de delimitar o seu alcance é relacioná-lo, juntamente com as "lei vigentes", ao ordenamento jurídico brasileiro.

De maneira mais direta, a ideia é impedir que se chegue a acordos ilegais. Isso não significa que as partes não possuam margem de negociação, sob o pretexto de que o ordenamento aponte para uma resposta única. Tal conclusão não encontra amparo na hermenêutica jurídica moderna, nem mesmo o legislador tem tal ambição. Dentro da moldura da lei, cada conflito admite uma multiplicidade de soluções que se harmonizam com os ditames do direito positivo. ${ }^{33}$

Esse princípio pode ser relacionado a necessária licitude do objeto do negócio e ao respeito da forma prescrita ou não defesa em lei (arts. 104 e 166, IV, do CC/2002). Por exemplo, a celebração de um acordo que defina que a transferência de um imóvel de valor superior a trinta vezes o maior salário mínimo será considerada perfeita independentemente de escritura pública (art. 108 do CC/2002).

\section{Conclusões}

O diálogo mais profundo entre os meios de gestão consensual de conflitos e as normas processuais estimulada pela institucionalização judicial da conciliação e da mediação permitiram a construção de fundamentos de interação sistêmica entre ambos. A sessões judiciais voltadas à promoção da autocomposição assumem a condição de ato processual, e como tal, atraem a incidência do princípio do devido processo legal.

33 Adverte Carlos Eduardo de Vasconcelos: "A dinâmica e os fundamentos da mediação de conflitos não afrontam ou desconhecem a validade dos textos do direito positivo, mas com eles não se confundem, pois a substância do método da mediação está na tópica, na problematização, na consideração teleológica a partir do legítimo protagonismo transdisciplinar das pessoas envolvidas nas circunstâncias existenciais do conflito e do diálogo". (VASCONCELOS, Carlos Eduardo de. Mediação de conflitos e práticas restaurativas. 5. ed. São Paulo: Método, 2017, p. 226). 
Ainda que os métodos autocompositivos divirjam em algumas características do processo judicial por possuir uma natureza voluntária, não adversarial, autocompositiva e esteja pautada por uma informalidade procedimental, não perde seu caráter de processo, nem se torna incompatível com a realidade judicial. Porém, é preciso definir a forma de interação dessas duas realidades, pois não é possível simplesmente formalizar e procedimentalizar toda a autocomposição sob pena de desvirtuá-la e torná-la menos eficiente em seus propósitos.

A lógica autocompositiva destoa das práticas consolidadas no Poder Judiciário. No entanto, a pretensões de adequação de metodologia para a sua incorporação à realidade jurídica não podem ser acolhidas acriticamente. A relação entre a autocomposição e o processo judicial não é de aglutinação, mas de diálogo, de coexistência.

Ao assumir a condição de uma etapa do processo judicial, a conciliação e mediação não podem ignorar a necessidade de adequação ao devido processo legal. Do estudo dos princípios informadores da mediação judicial e dos processos de mediação, foi possível concluir que ela atende aos preceitos do devido processo legal, apresentando-se em diversos aspectos como capaz de assegurar os valores de forma até mais efetiva que a própria jurisdição.

O devido processo legal se manifesta de forma diferente e com menos intensidade. Ele pode ser extraído de alguns princípios informadores da conciliação e mediação relacionados à regularidade do procedimento, quais sejam: imparcialidade do mediador e do conciliador, independência, autonomia privada, isonomia, confidencialidade, boa-fé, decisão informada e respeito à ordem pública e às leis vigentes.

Isso não significa que qualquer nível de violação desses princípios acarrete necessariamente a anulação do acordo eventualmente firmado. Essa consequência somente será verificada quando o defeito no caso concreto demonstrar prejuízo efetivo, pois o devido processo legal não pode ser utilizado para subsidiar o mero arrependimento.

\section{Referências}

ALMEIDA, Diogo Assumpção Rezende de. O princípio da adequação e os métodos de solução de conflitos. Revista de Processo, São Paulo, v. 36, n. 195, p. 185-208, maio 2011.

BUSH, Robert A. Baruch; FOLGER, Joseph P. Mediação transformativa e intervenção de terceiros: as marcas registradas de um profissional transformador. In: SCHNITMAN, Dora Fried; LITTLEJOHN, Stephen. Novos paradigmas em mediação. Porto Alegre: ArtMed, 1999.

CALMON, Petrônio. Fundamentos da mediação e da conciliação. Rio de Janeiro: Forense, 2013.

CORRÊA, Marina Beatriz Pereira e CORDEIRO, Raquel Helena Duarte. Os princípios orientadores da mediação no novo Código de Processo Civil e as garantias constitucionais. In: PINHO, Humberto Dalla Bernardina; SANTANNA, Ana Carolina Squadri; SOBREIRA, Eneisa Miranda Bittencourt; PAUMGARTTEN, Michele Pedrosa. (org.). Mediação judicial e garantias constitucionais. Niterói RJ: PPGSD, 2013.

DIDIER JR., Fredie. Curso de Direito Processual Civil: introdução ao direito processual civil, parte geral e processo de conhecimento. 22. ed. Salvador: JusPODIVM, 2020.

CALAMANDREI, Piero. Direito Processual Civil: estudos sobre o processo civil. Tradução de Luiz Abezia e Sandra Drina Fernandez Barbery. Ciência do Processo, v. 1. Campinas: Bookseller, 1999.

CALMON, Petrônio. Fundamentos da mediação e da conciliação. Rio de Janeiro: Forense, 2013.

CRESPO, Mariana Hernandez. Perspectiva sistêmica dos métodos alternativos de resolução de conflitos na América Latina: aprimorando a sombra da lei através da participação do cidadão In: ALMEIDA, Rafael Alves de; ALMEIDA, Tania; CRESPO, Mariana Hernandez (org.). Tribunal multiportas: investindo no capital social para maximizar o sistema de solução de conflitos no Brasil. Rio de Janeiro: FGV, 2012. 
FILPO, Klever Paulo Leal. Mediação judicial: discursos e práticas. Rio de Janeiro: Mauad-Faperj, 2016.

GAJARDONI, Fernando da Fonseca. Comentário ao art. 173. In: GAJARDONI, Fernando da Fonseca; DELLORE, Luiz; ROQUE, André Vasconcelos; OLIVEIRA JR., Zulmar Duarte de (coord.). Teoria geral do processo: comentários ao CPC de 2015. Rio de Janeiro: Forense, 2017.

KAMEL, Antoine Youssef. Mediação e arbitragem. Curitiba: InterSaberes, 2017.

MIRANDA NETTO; Fernando Gama de; SOARES; Irineu Carvalho de Oliveira. Princípios procedimentais da mediação no Novo Código de Processo Civil. In: ALMEIDA, Diogo Assumpção Rezende de; PANTOJA, Fernanda Medina; PELAJO, Samantha (coord.). A mediação no Novo Código de Processo Civil. 2. ed. Rio de Janeiro: Forense, 2016.

NEVES, Daniel Amorim Assumpção. Manual de direito processual civil: volume único. 8. ed. Salvador: JusPodivm, 2016.

MOORE, Christopher W. O processo de mediação: estratégias práticas para a resolução de conflitos. 2. ed. Porto Alegre: Artmed, 1998.

MEIRELLES, Delton Ricardo Soares; MIRANDA NETTO; Fernando Gama de. Mediação judicial no projeto do novo Código de Processo Civil. Revista de Arbitragem e Mediação, São Paulo, v. 9, n. 33, p. 213-236, abr./jun. 2012.

PEIXOTO, Ravi. Os "princípios” da mediação e da conciliação. In: ZANETI JR., Hermes; CABRAL, Trícia Navarro Xavier (coord.). Justiça multiportas: mediação, conciliação, arbitragem e outros meios de solução adequada de conflitos. Salvador: JusPODIVM, 2016.

RAATZ, Igor. Autonomia privada e processo: liberdade, negócios jurídicos processuais e flexibilização procedimental. 2a edição. Salvador: Juspodivm, 2019, p. 162. No mesmo sentido: CABRAL, Érico de Pina. A “autonomia” no direito privado. Revista de Direito Privado, São Paulo, v. 19, n. 5, p. 83-129, jul./set. 2004.

REUBEN, Richard. Constitutional gravity: a unitary theory of alternative dispute resolution and public justice. p. 949-1104. UCLA Law Review, v. 47, 2000.

SANTANNA, Ana Carolina Squadri; VERAS, Cristina Vianna; MARQUES, Giselle Picorelli Yacoub. Independência e imparcialidade: princípios fundamentais da mediação. In: ALMEIDA, Diogo Assumpção Rezende de; PANTOJA, Fernanda Medina; PELAJO, Samantha (coord.). A mediação no Novo Código de Processo Civil. 2. ed. Rio de Janeiro: Forense, 2016.

SALES, Lília Maia de Morais. Justiça e mediação de conflitos. Belo Horizonte: Del Rey, 2003.

SICA, Heitor Vitor Mendonça. Velhos e novos institutos fundamentais do direito processual civil. In: ZUFELATO, Camilo; YARSHELL, Flávio Luiz (org.). 40 anos da teoria geral do processo no Brasil: passado, presente e futuro. São Paulo: Malheiros, 2013.

TARTUCE, Fernanda. Mediação nos conflitos civis. 2. ed. São Paulo: Método, 2015.

VASCONCELOS, Carlos Eduardo de. Mediação de conflitos e práticas restaurativas. 5. ed. São Paulo: Método, 2017.

WATANABE, Kazuo. Modalidade de mediação. In: DELGADO, José et al. (coord.). Mediação: um projeto inovador. Brasília, DF: Centro de Estudos Judiciários, 2003. 